\title{
Intramolecular Alkoxycyanation and Alkoxyacylation Reactions: New Types of Alkene Difunctionalizations for the Construction of Oxygen Heterocycles
}

\author{
John P. Wolfe*
}

alkenes $\cdot$ catalysis $\cdot$ heterocycles $\cdot$ ketones $\cdot$ nitriles

$S_{\mathrm{a}}$ dihydrobenturans, are dihydrobenzofurans, are important motifs in a myriad of biologically active compounds, including natural products and pharmaceutical targets. Therefore, there has been considerable interest in the development of new synthetic methods for the construction of these important structures. ${ }^{[1]}$ Many traditional approaches to the generation of these compounds involve ring formation through intramolecular $\mathrm{S}_{\mathrm{N}} 2$ reactions and related strategies. However, these approaches typically lead to the formation of only one bond during ring closure and often require somewhat complicated substrates. ${ }^{[1]}$

Late transition metal catalyzed alkene carboalkoxylations are a subclass of alkene difunctionalization reactions ${ }^{[2]}$ that have considerable utility for the construction of tetrahydrofurans, dihydrobenzofurans, and related oxygen heterocycles. These reactions effect formation of a $\mathrm{C}-\mathrm{O}$ bond during ring closure along with a $\mathrm{C}-\mathrm{C}$ bond adjacent to the ring and up to two stereocenters (Scheme 1). In most instances these transformations involve the coupling of an alcohol that bears

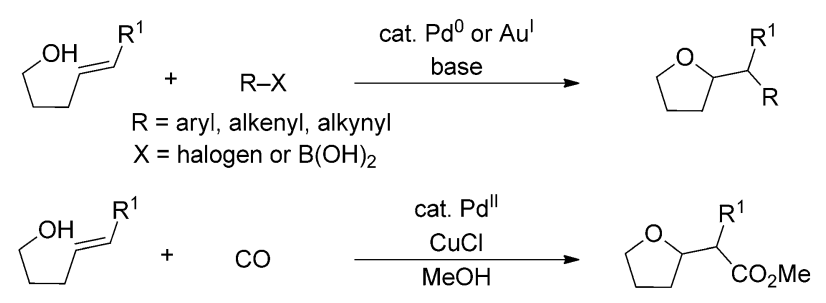

Scheme 1. Metal-catalyzed alkene carboalkoxylation reactions between unsaturated alcohols and exogenous carbon electrophiles.

a pendant alkene with an exogenous carbon electrophile, such as an aryl-, alkenyl-, or alkynyl halide. ${ }^{[3,4]}$ Introduction of an ester functionality has also been accomplished by using $\mathrm{CO}$ as the carbon electrophile. ${ }^{[5]}$

Recently, the groups of Douglas and Nakao have independently developed two complementary new strategies for metal-catalyzed alkene carboalkoxylation reactions that do

[*] Prof. Dr. J. P. Wolfe

Department of Chemistry, University of Michigan

930 N. University Ave, Ann Arbor, MI 48109-1055 (USA)

E-mail: jpwolfe@umich.edu not require an exogenous carbon electrophile. ${ }^{[6,7]}$ Instead, the carbon electrophile is covalently attached to the cyclizing oxygen atom in the substrate, and the carboalkoxylations are accomplished through activation of this $\mathrm{C}-\mathrm{O}$ bond by the catalyst. Importantly, these two approaches lead to the formation of dihydrobenzofuran derivatives that bear functional groups (ketones or nitriles), which are convenient handles for further elaboration of the molecule, and cannot be directly installed by using previously developed alkene carboalkoxylation methods.

The method of the Douglas group involves the use of a cationic $\mathrm{Rh}^{\mathrm{I}}$ complex to catalyze the intramolecular alkoxyacylation of acylated 2-allylphenol derivatives (Scheme 2). ${ }^{[6]}$ These reactions afford 2-acylmethyl dihydrobenzofuran derivatives in good yield (51-90\%), and are also

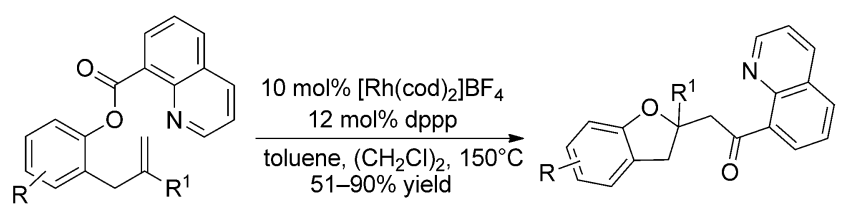

Scheme 2. Rhodium-catalyzed intramolecular alkene alkoxyacylation reactions developed by Douglas. cod $=1,5$-cyclooctadiene, dppp $=$ propane-l,3-diylbis (diphenylphosphane).

effective for formation of analogous chroman and benzodioxin products (although the yield of the benzodioxin is modest). However, at this point in time, the presence of a quinoline directing group on the acyl unit of the substrate is required for successful product generation. This group helps to prevent competing decarbonylation side reactions of intermediate acylrhodium species, and may also play a role in catalyst binding to direct the $\mathrm{C}-\mathrm{O}$ bond activation.

The Nakao group employed a related strategy for the generation of 2-cyanomethyl dihydrobenzofuran derivatives (Scheme 3). In this case, cyanates derived from 2-allylphenols were used as substrates, and intramolecular alkoxycyanation reactions were effected by using a dual catalyst system composed of $\left[\mathrm{Pd}_{2}(\mathrm{dba})_{3}\right] /$ Xantphos $(10 \mathrm{~mol} \%)$ and $\mathrm{BPh}_{3}$ $(20 \mathrm{~mol} \%) .{ }^{[7]}$ The palladium catalyst is involved in the key bond-forming events, and the $\mathrm{BPh}_{3}$ Lewis acid catalyst binds to the nitrile and facilitates insertion of the palladium 


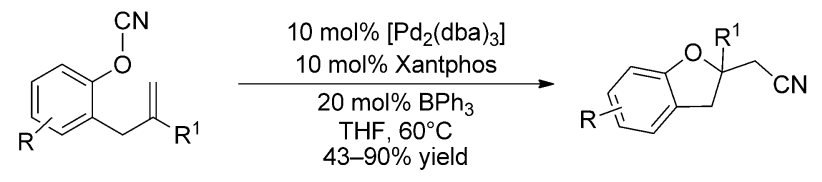

Scheme 3. Palladium-catalyzed intramolecular alkene alkoxycyanation reactions developed by Nakao. dba=trans,trans-dibenzylideneacetone.

complex into the cyanate $\mathrm{O}-\mathrm{CN}$ bond. The products are generated in moderate to good yield, and the authors illustrate the feasibility of forming both five- and sixmembered rings. The reaction conditions are sufficiently mild to tolerate the presence of ester functional groups, and halogen substituents $(\mathrm{F}, \mathrm{Cl}, \mathrm{Br})$ on the aromatic ring are not cleaved during these transformations. However, chemical yields are slightly lower for reactions of these functionalized substrates (43-79\%) as compared to unfunctionalized derivatives $(60-90 \%)$.

Both the intramolecular alkoxyacylation and alkoxycyanation reactions described by Douglas and Nakao, respectively, appear to proceed through similar mechanistic pathways (Scheme 4). In both cases, the O-FG bond undergoes oxidative addition to the low-valent metal catalyst to generate

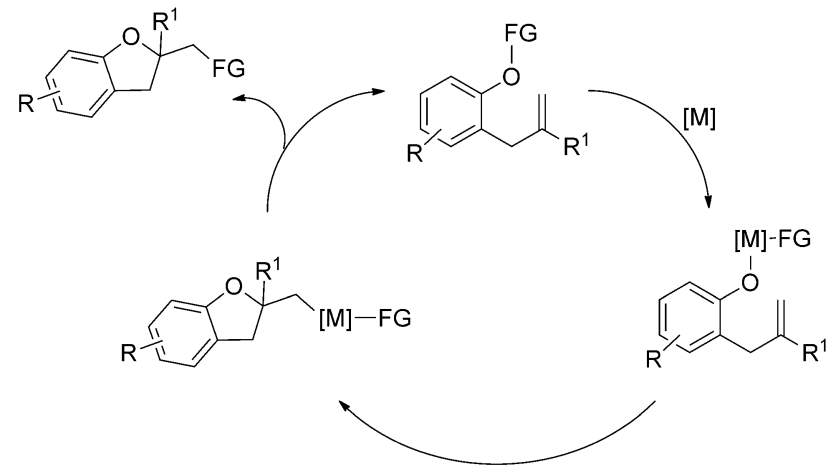

Scheme 4. Mechanism of intramolecular alkene alkoxyfunctionalization reactions. $\mathrm{FG}=$ functional group, $\mathrm{M}=$ metal.

an intermediate metal alkoxide complex.$^{[8]}$ Migratory insertion of the alkene into the $\mathrm{M}-\mathrm{O}$ bond ${ }^{[4, b, 9]}$ followed by $\mathrm{C}-\mathrm{FG}$ bond-forming reductive elimination then provides the functionalized heterocyclic products. This mechanism is related to that of other late transition metal catalyzed carboalkoxylation reactions, ${ }^{[4]}$ but differs in the route by which the key metal alkoxide intermediate is formed.

As is the case with all new synthetic methods, the scope of these new transformations has not yet been fully explored, and many challenging problems have yet to be addressed. In contrast to other late transition metal catalyzed carboalkoxylations, the new alkoxyfunctionalization reactions are currently limited to the construction of heterocycles that bear fused aryl rings. In addition, substitution at the internal alkene carbon atom is required to prevent competing $\beta$-hydrideelimination side reactions. Diastereoselective or enantioselective versions of these reactions are also certain to be a focus of future investigations in this area. Nonetheless, the new intramolecular alkene alkoxyfunctionalization reactions developed by Douglas and Nakao represent a significant conceptual advance in the field. These transformations allow introduction of ketone or cyano groups into the heterocyclic products, and proceed under relatively mild conditions, as no added base is required to facilitate these reactions. The strategy of heterocycle formation through metal-catalyzed alkene insertion into a heteroatom-containing functional group bond has considerable potential utility, and will likely find many applications in both reaction development and complex molecule synthesis.

Received: June 8, 2012

Published online: September 5, 2012

[1] a) J. P. Wolfe, M. B. Hay, Tetrahedron 2007, 63, 261-290; b) F. Bertolini, M. Pineschi, Org. Prep. Proc. Int. 2009, 41, 385-418.

[2] K. H. Jensen, M. S. Sigman, Org. Biomol. Chem. 2008, 6, $4083-$ 4088.

[3] For reviews, see: a) R. I. McDonald, G. Liu, S. S. Stahl, Chem. Rev. 2011, 111, 2981-3019; b) J. P. Wolfe, Synlett 2008, $2913-$ 2937.

[4] a) J. P. Wolfe, M. A. Rossi, J. Am. Chem. Soc. 2004, 126, 16201621; b) M. B. Hay, J. P. Wolfe, J. Am. Chem. Soc. 2005, 127, 16468-16476; c) S. Hayashi, H. Yorimitsu, K. Oshima, J. Am. Chem. Soc. 2009, 131, 2052-2053; d) G. Zhang, L. Cui, Y. Wang, L. Zhang, J. Am. Chem. Soc. 2010, 132, 1474-1475; e) S. Nicolai, J. Waser, Org. Lett. 2011, 13, 6324-6327.

[5] a) M. F. Semmelhack, C. Bodurow, J. Am. Chem. Soc. 1984, 106, 1496-1498; b) M. F. Semmelhack, N. Zhang, J. Org. Chem. 1989, $54,4483-4485$.

[6] G. T. Hoang, V. J. Reddy, H. H. K. Nguyen, C. J. Douglas, Angew. Chem. 2011, 123, 1922-1924; Angew. Chem. Int. Ed. 2011, 50, $1882-1884$.

[7] D. C. Koester, M. Kobayashi, D. B. Werz, Y. Nakao, J. Am. Chem. Soc. 2012, 134, 6544-6547.

[8] a) N. Chatani, H. Tatamidani, Y. Ie, F. Kakiuchi, S. Murai, J. Am. Chem. Soc. 2001, 123, 4849-4850; b) T. Yamamoto, S. Miyashita, Y. Naito, S. Komiya, T. Ito, A. Yamamoto, Organometallics 1982, $1,808-812$; c) K. Fukumoto, A. A. Dahy, T. Oya, K. Hayasaka, M. Itazaki, N. Koga, H. Nakazawa, Organometallics 2012, 31, $787-790$.

[9] a) T. Hayashi, K. Yamasaki, M. Mimura, Y. Uozumi, J. Am. Chem. Soc. 2004, 126, 3036-3037; b) R. M. Trend, Y. K. Ramtohul, B. M. Stoltz, J. Am. Chem. Soc. 2005, 127, 17778-17788; c) P. Zhao, C. D. Incarvito, J. F. Hartwig, J. Am. Chem. Soc. 2006, 128, $9642-9643$. 